\begin{tabular}{lcl}
\hline Bentham OPEN & Open Medicine Journal \\
CrossMark & Content list available at: www.benthamopen.com/MEDJ/ & $\begin{array}{l}\text { Open } \\
\text { Medine } \\
\text { lournal }\end{array}$ \\
\hline
\end{tabular}

RESEARCH ARTICLE

\title{
Physicians' Adherence to Asthma Guidelines: A Prospective Prescription Review from Tertiary Care Hospital, Malaysia
}

\author{
Raja Ahsan Aftab ${ }^{1,2, *}$, Amer Hayat Khan ${ }^{1}$, Syed Azhar Syed Sulaiman ${ }^{1}$ and Irfhan $\mathrm{Ali}^{3}$ \\ ${ }^{I}$ Department of Clinical Pharmacy, School of Pharmaceutical Sciences Universiti Sains Malaysia, 11800 Penang, \\ Malaysia \\ ${ }^{2}$ School Of Pharmacy, Taylor's University, Subang Jaya, Selangor, Malaysia \\ ${ }^{3}$ Department of Respiratory Medicine, Penang General Hospital, Penang, Malaysia
}

Received: January 11, 2018

Revised: April 16, 2018

Accepted: April 23, 2018

\begin{abstract}
:
Aims and objective:

The aim of the current study is to evaluate adherence clinical practice guideline of asthma, to assess treatment outcomes of guideline adhering to pharmacotherapy and to calculate the cost of asthma treatment.
\end{abstract}

\section{Methods:}

A prospective record viewing study was conducted at the respiratory clinic of Hospital Pulau Pinang, Penang, Malaysia from December 2012 to June 2013. A total of 180 prescriptions of patients from 6 doctors (30 prescriptions by each doctor) were evaluated against global initiative of asthma (GINA) guidelines. Treatment outcomes of asthma patients were evaluated based on lung function values. Direct assessment of cost was compared between the guidelines adhered and non-adhered scripts.

\section{Results:}

Of the total 180 asthmatic patients, 143 (78.9\%) received guideline-adhered pharmacotherapy. A total of 158 (87.7\%) patients reported successful treatment outcome, out of which, 124 (78.4\%) patients received guideline-adhered pharmacotherapy. A statistical significant difference $(\mathrm{p}<0.001)$ was observed among lung function values after patients' first and second visit. An analysis indicated that patients aged $>46$ years were found to have a significant association with treatment outcomes $(\mathrm{OR}=3.77, \mathrm{p}=0.03)$. While comparing the cost of asthma treatment outcome, it was observed that the average cost of successfully treated patients who received guideline-adhered pharmacotherapy was RM 70.00 per patient (1US\$ = RM 3.20) while patients reporting unsuccessful treatment outcome was RM 75.47 per patient.

\section{Conclusion:}

A majority of asthma patients received guideline-adhered pharmacotherapy.

Keywords: Physicians' adherence, Asthma clinical practice guideline, Asthma treatment outcomes, Asthma medication cost, Pharmacotherapy, GINA guidelines.

\section{INTRODUCTION}

Asthma is regarded as a chronic disease and affects 334 million people globally [1]. There is a continuous rise in the epidemiology of asthma globally and the number of patients affected are expected to reach 400 million by 2025 [1]. The burden of asthma is greatest for children 10-14 years and elderly aged 75-79 years. Moreover, 4.5\% of young adults have either been diagnosed with asthma and/or taking asthma medication [2]. In addition to the life-threatening

\footnotetext{
* Address correspondence to this author at the Department of Clinical Pharmacy, School of Pharmaceutical Sciences, Universiti Sains Malaysia,
} 11800 Penang, Malaysia, Tel: 006-010-4322719;, Fax: 00604657 0017, Email: ahsan1025@yahoomail.com 
consequences, asthma produces a major economic burden on healthcare systems around the world. In the USA, asthma has a significant economic burden with a total cost of USD 81.9 billion in 2013, including those incurred by absenteeism and mortality [3]. Similarly, the cost of treating asthma in Europe is USD 21.65 billion annually [4]. Reducing asthma mortality requires a reduction in treatment variability among asthma patients and emphasis is needed in selecting cost-effective medication that can reduce the cost of asthma treatment.

To homogenize clinical practices with evidence-based medicines, Clinical Practice Guideline (CPG) were developed and implemented in various healthcare settings around the globe $[5,6]$. The primary objective of CPG is to improve patients' condition and provide cost-effective therapeutic plans. Ever since the development and implementation of clinical practice guidelines took place, healthcare practitioners have provided constant feedback to rationalize their use. Studies have indicated that the success of CPG implementation has actually improved patients management [7]. However, treatment outcomes of guideline adhered and non-adhered pharmacotherapy are rarely evaluated in the Malaysian healthcare system [8 - 11].

Therefore, the current study is aimed to assess physicians' adherence to GINA guidelines and to evaluate treatment outcomes and cost related to guideline-adhered pharmacotherapy among patients visiting a public healthcare institute in the state of Penang, Malaysia.

\section{METHODOLOGY}

\subsection{Study Design, Sampling and Settings}

The study was designed as a prospective prescription analysis at Hospital Pulau Pinang, Malaysia, from December 2012 to June 2013. All six Medical Officers (MO) from respiratory clinic of Hospital Pulau Penang were included for the prescription analysis of 180 chronic asthma patients (30 patient prescriptions per doctor). Since these Medical Officers (MO) spent three months at the respiratory clinic before being rotated to other departments; a decision was taken to enroll 30 patients per doctors. The study purpose was explained and informed consent was obtained before enrolling study participants.

\subsection{Inclusion Criteria, Time Frame and Data Review}

All patients with asthma visiting the respiratory clinic from December 2012 to June 2013 were included in the current study. Due to complications and organisational constraints, pregnant asthma patients were excluded from the study. A thorough review of patients' medical records was conducted to note multiple patient characteristics to categorize patients' asthma control (controlled, partial controlled and uncontrolled) based on GINA guideline. Once patients' asthma control was categorized, physicians' treatment to patients' asthma control and prescribed medication were noted to indicate adherence with the GINA guideline. Each prescription was then termed either as "adhered" or "non-adhered".

All enrolled patients were followed for a second visit (after 3 months) to monitor their lung function values (FEV1). Patients' lung function values were categorised as controlled $(>80 \%)$, partially controlled $(<80 \%)$ and uncontrolled $(<60 \%)$. Patients with controlled and partially-controlled asthma at the second visit were categorised as successfully treated, whereas patients with uncontrolled asthma were categorised as unsuccessfully treated. The costing only included direct asthma medication cost, and all prescribed medications were recorded and the price was confirmed by the hospital pharmacy.

\subsection{Data Analysis}

The data was analyzed using Statistical Package for Social Sciences v 20.0. The categorical data was presented as frequencies and percentage while the continuous data was reported as mean and Standard Deviation (SD). Chi- square and Fischer's Exact test was used to detect statistically significant association between variables where applicable. Univariate analysis was conducted to identify the effective variable towards treatment outcomes. Paired sample t-test was used to identify any significant changes in lung function values from the $1^{\text {st }}$ and $2^{\text {nd }}$ visit. A p-value of less than 0.05 was considered as statistically significant.

\subsection{Ethical Approval}

The study was approved by the Ministry of Health and Medical Research Ethics Committee (MREC) Malaysia NMRR-12-1266-14166 


\section{RESULTS}

Altogether 6 doctors from the respiratory department of Hospital Pulau Penang were included in the current study among them, 4 were $4(66.6 \%)$ male and $2(33.3 \%)$ were female doctors (Mean age $32 \mathrm{SD} \pm 2.13$ ). The mean asthma guideline adherence score was $23.8(\mathrm{SD} \pm 2.3)$ Table 1. Of the total 180 patients, $143(78.9 \%)$ patients received guideline-adhered pharmacotherapy

Table 1. Guideline adherence scores by respiratory department doctors.

\begin{tabular}{|c|c|}
\hline Doctor & Adherence scores \\
\hline Doctor 1 & 22 \\
\hline Doctor 2 & 25 \\
\hline Doctor 3 & 23 \\
\hline Doctor 4 & 28 \\
\hline Doctor 5 & 22 \\
\hline Doctor 6 & 23 \\
\hline Mean \pm SD 23.8 \pm 2.3 & \\
\hline
\end{tabular}

\subsection{Difference of Lung Function Values (First and Second Visit)}

The mean lung function value at the first visit was $1.24(\mathrm{SD} \pm 0.51)$ whereas it increased to $1.59(\mathrm{SD} \pm 0.52)$ at the second visit. Paired sample $t$ test indicated a highly positive significant difference $(p<0.001)$ in lung function values after the first and second visit (Table 2).

Table 2. lung function values at first and second visit.

\begin{tabular}{|c|c|c|}
\hline Variables & Mean $( \pm$ SD) & p- value \\
\hline $1^{\text {st }}$ visit & $1.24(0.51)$ & $<0.001$ \\
\hline $2^{\text {nd }}$ visit & $1.59(0.52)$ & \\
\hline
\end{tabular}

\subsection{Treatment Outcome and Cost of Asthma Treatment}

Of the total 180, $158(87.7 \%)$ patients' treatment outcome was successful. Among the patients successfully treated, $124(78.4 \%)$ patients received guideline-adhered pharmacotherapy. However, 22 (22.3\%) patients' treatment outcome was unsuccessful, of which $19(86.3 \%)$ patients received guideline-adhered pharmacotherapy whereas, 3 patients did not receive guideline-adhered pharmacotherapy (Table 3 ).

Table 3. Treatment outcomes and adherence to asthma guideline.

\begin{tabular}{|c|c|c|c|c|}
\hline Lung Function (FEV1) & $\begin{array}{c}\text { Total } \\
\text { N (\%) }\end{array}$ & Treatment Outcome* & $\begin{array}{c}\text { Guideline Adhered } \\
\text { N (\%) }\end{array}$ & $\begin{array}{c}\text { Guideline Non Adhered } \\
\text { N (\%) }\end{array}$ \\
\hline Second visit & & & & $34(21.6)$ \\
\hline$>80 \%$ & $158(87.7)$ & Successful & $124(78.4)$ & \\
\hline$<80 \%$ & & & & $19(86.3)$ \\
\hline$<60 \%$ & $22(22.3)$ & Unsuccessful & $(12.7)$ \\
\hline
\end{tabular}

*Practices at respiratory department were based on patient asthma control. Lung function values of patients as $>80 \%,<80 \%$ and $<60 \%$ were categorised as controlled, partial controlled and uncontrolled respectively. Patients with controlled and partial controlled asthma were categorised as successfully treated where as patients with uncontrolled asthma were categorised as unsuccessfully treated

Table 4 presents the details of treatment cost. Of the patients successfully treated, the treatment cost of 124 patients who received guideline-adhered pharmacotherapy was RM 8680.32 (average cost RM 70.00/ patient). Moreover, the cost of asthma treatment among $19(10.8 \%)$ unsuccessfully treated patients who received guideline-adhered pharmacotherapy was RM 1433.98 (average cost RM 75.47/ patient) (Table 4).

Table 4. Cost of asthma treatment based on treatment outcomes and guideline adherence.

\begin{tabular}{|c|c|c|c|c|c|c|}
\hline Treatment Outcome & $\begin{array}{c}\text { Guideline Adherence } \\
\text { N (\%) }\end{array}$ & \begin{tabular}{c|} 
Total Cost \\
RM \\
\end{tabular} & $\begin{array}{c}\text { Average Cost/ patient } \\
\text { RM }\end{array}$ & $\begin{array}{c}\text { Guideline Non Adherence } \\
\text { N (\%) }\end{array}$ & $\begin{array}{c}\text { Total Cost } \\
\text { RM } \\
\end{array}$ & $\begin{array}{c}\text { Average Cost Per } \\
\text { Patient } \\
\text { RM }\end{array}$ \\
\hline Successful & $124(68.8)$ & 8680.32 & 70.00 & $34(18.8)$ & 479.84 & 14.11 \\
\hline
\end{tabular}


(Table 4) contd.....

\begin{tabular}{|c|c|c|c|c|c|c|}
\hline Treatment Outcome & $\begin{array}{c}\text { Guideline Adherence } \\
\text { N (\%) }\end{array}$ & $\begin{array}{c}\text { Total Cost } \\
\text { RM } \\
\end{array}$ & $\begin{array}{c}\text { Average Cost/ patient } \\
\text { RM }\end{array}$ & $\begin{array}{c}\text { Guideline Non Adherence } \\
\text { N (\%) }\end{array}$ & $\begin{array}{c}\text { Total Cost } \\
\text { RM } \\
\end{array}$ & $\begin{array}{c}\text { Average Cost Per } \\
\text { Patient } \\
\text { RM }\end{array}$ \\
\hline Unsuccessful & $19(10.8)$ & 1433.98 & 75.47 & $3(1.6)$ & 40.95 & 13.65 \\
\hline
\end{tabular}

\subsection{Patients' Factors Affecting Treatment Outcomes}

Of the 152 successfully treated patients, the cohort was dominated by females 104 (88.1\%). A majority belonged to the Malay ethnic group $(n=82,88.1 \%)$ and were categorized in the age group of $36-45$ years $(n=99,83.8 \%)$. However, there was no statistical significance reported $(\mathrm{p}>0.005)$ among study variables and treatment outcome (Table 5).

Table 5. Association between patient variables and treatment outcomes

\begin{tabular}{|c|c|c|c|}
\hline- & \multicolumn{2}{|c|}{ Treatment outcomes } & \multirow[b]{2}{*}{ *P value } \\
\hline Patient variable & $\begin{array}{c}\text { Successful } \\
\text { N (\%) }\end{array}$ & $\begin{array}{c}\text { Unsuccessful } \\
\text { N }(\%)\end{array}$ & \\
\hline \multicolumn{4}{|l|}{ Gender } \\
\hline Male & $54(87)$ & $8(13)$ & 0.84 \\
\hline Female & $104(88.1)$ & $14(11.9)$ & \\
\hline \multicolumn{4}{|l|}{ Ethnicity } \\
\hline Malays & $82(88.1)$ & $11(11.9)$ & 0.43 \\
\hline Chinese & $43(91.4)$ & $4(8.6)$ & \\
\hline Indian & $33(82.5)$ & $7(17.5)$ & \\
\hline \multicolumn{4}{|l|}{ Age-group } \\
\hline$<25$ years & $10(91)$ & $1(9)$ & 0.17 \\
\hline 25-35 years & $25(96.1)$ & $1(3.9)$ & \\
\hline $36-45$ years & $24(96)$ & $1(4)$ & \\
\hline $46 \&$ above & $99(83.8)$ & $19(16.2)$ & \\
\hline Smoker & $38(88.3)$ & $5(11.7)$ & 0.88 \\
\hline \multicolumn{4}{|l|}{ Co-morbidity } \\
\hline Hypertension & $24(80)$ & $6(20)$ & $0.21 * *$ \\
\hline Diabetes & $30(88.2)$ & $4(11.8)$ & 0.9 \\
\hline COPD & $32(86.4)$ & $5(13.6)$ & 0.7 \\
\hline
\end{tabular}

*Chi square, ** Fisher exact test

On further analysis to identify variables within patient characteristics that may affect treatment outcome, univariate analysis indicated that no patient variable was associated with treatment outcome. However, patients aged $>46$ years were found to have a significant association with treatment outcomes (OR 3.77, p 0.03) (Table 6).

Table 6. Patient variables affecting treatment outcomes (Univariate analysis).

\begin{tabular}{|c|c|c|c|}
\hline- & \multicolumn{2}{|c|}{ Treatment Outcomes } & \multirow[b]{2}{*}{ P value } \\
\hline Patient Variable & OR & $95 \%$ CI & \\
\hline \multicolumn{4}{|l|}{ Gender } \\
\hline Female & 1.10 & $0.43-2.78$ & 0.84 \\
\hline \multicolumn{4}{|l|}{ Male } \\
\hline \multicolumn{4}{|l|}{ Ethnicity } \\
\hline Malays & 0.92 & $0.38-2.26$ & 0.86 \\
\hline Chinese & 0.59 & $0.19-1.85$ & 0.37 \\
\hline Indian & 1.76 & $0.66-4.69$ & 0.25 \\
\hline \multicolumn{4}{|l|}{ Age-group } \\
\hline$<25$ years & 0.70 & $0.08-5.78$ & 0.74 \\
\hline $25-35$ years & 3.94 & $0.5-30.69$ & 0.19 \\
\hline $36-45$ years & 0.26 & $0.03-2.07$ & 0.20 \\
\hline $46 \&$ above & 3.77 & $1.07-13.3$ & 0.03 \\
\hline Smoker & 0.92 & $0.32-2.68$ & 0.89 \\
\hline
\end{tabular}


(Table 6) contd.....

\begin{tabular}{|c|c|c|c|}
\hline- & \multicolumn{2}{|c|}{ Treatment Outcomes } \\
\hline Patient Variable & OR & 95\%CI & \\
\hline Co-morbidity & & $0.74-5.88$ & 0.16 \\
\hline Hypertension & 2.1 & $0.29-2.97$ & 0.91 \\
\hline Diabetes & 0.94 & $0.39-3.37$ & 0.78 \\
\hline COPD & 1.15 & & 0.1 \\
\hline
\end{tabular}

\section{DISCUSSION}

Unlike previous studies that assessed doctor guidelines adherence by survey $[12,13]$ or a questionnaire $[14,15]$ was often subjected to bias, the current study evaluated doctor guidelines adherence by assessing prescribing practices (prescription analysis) of doctors with CPG (GINA 2011) recommendations. A majority of the patients received pharmacotherapy in recommendations with CPG (GINA 2011). When compared to previously conducted studies elsewhere, the current study indicates better adherence to CPG [16 - 18].

Translating CPG to clinical practice and assessing treatment outcomes are critical processes that form the basis for the development of future guidelines. Studies demonstrate that a majority of patients with uncontrolled asthma and a wide range of severities can gain guideline-defined treatment and management goals [19]. Our findings indicate that altogether, $158(87.7 \%)$ patients' treatment outcome was successful and achieved guideline-recommended treatment goals. A total of 158 patients' treatment outcome was successful that represented both patients with guideline-adhered and non-adhered pharmacotherapy. A study by Stone et al. suggests that patient on GINA Step 4 and 5 treatment plans may require additional pharmacotherapies to manage uncontrolled asthma [20]. An important finding from our study was 34 patients who did not receive guideline-adhered pharmacotherapy, and yet, their treatment outcome was successful. Since the main purpose of this clinical practice guideline is to provide a standardised treatment and to increase quality of life, doctors in clinical practice often face a scenario which makes them deviate from standard guideline protocols and provide additional therapies and treatment plan to treat such patients [21]. In the current study, the doctors used their professional skills and experience to treat 34 asthma patients which resulted in successful treatment outcome. Another important aspect of this scenario is that doctors saved RM 479.84 (RM 14.11 average cost) that makes $4.6 \%$ of the total cost of asthma treatment. The current study only evaluates the direct cost associated with asthma treatment. However, if indirect cost is included, the overall expenses could have been much higher. In other words, doctors help save considerable cost per patient.

One of the possible reasons for nineteen (10.8\%) patients who received guideline adhered pharmacotherapy but had unsuccessful treatment outcome could be that these patients had hypertension $(78.9 \%)$, diabetes $(84.2 \%)$ and COPD $(84.2 \%)$ as comorbidities, and majority $(84.2 \%)$ of patients were aged $>46$ years. Studies have indicated that comorbidity affects treatment outcomes [22]. Similarly, $3(1.6 \%)$ patients did not receive adhered pharmacotherapy and their treatment outcome was unsuccessful and their mean age was 66.5 years. Studies indicate that lung function value decreases with age and is a common problem in elderly patients [23, 24], which might have been the reason for these 3 elderly patients to be treated differently. Doctors' experience in treating such patients can be a factor in determining treatment outcome.

In studying treatment outcome among asthma patients aged $>50$ years and $<50$ years, a study by Stephanie et al. reported that the rate of severe asthma exacerbations in patients aged $>50$ years reduced by $68.9 \%$ as compared to $75.4 \%$ in patients with age $<50$ years (p 0.001) [25]. Moreover, the reduction in asthma day symptoms and nocturnal awakenings in patients aged $>50$ years was $67.8 \%$ and $72.6 \%$ compared to $79.3 \%$ and $82.5 \%$ among younger asthma patients respectively [25]. The findings suggest that the younger patients are more responsive to treatment outcomes as compared to older patients. However, findings from the current study suggest that patients with the age group of $>46$ years had a significant association with treatment outcome. Since $65.5 \%$ of our enrolled asthma patients belonged to the age group of $>46$ years, which might explain a statistical association of age group with treatment outcomes.

The cost of asthma is greatest among patients with uncontrolled asthma. A study assessing a varying degree of asthma severity reported that $5-9 \%$ of patients had inadequately-controlled asthma but these patients accounted for $26-33 \%$ of the medical cost. Overall, inadequately-controlled asthma patients were 4-5 times more costly than adequately-controlled asthma patients [26, 27]. The cost of asthma treatment in the current study was high (RM 10,635.09). However, the cost of asthma treatment among guideline-adhered and successfully treated patients was less as compared to unsuccessfully treated patients. Moreover, $81 \%$ of asthma medication prescribed was a combination 
medication ( $\beta$ agonist + corticosteroid) which is expensive. Hence, careful selection of therapeutic regimen by doctors can help reduce asthma treatment cost.

One of the major limitations of the current study was the sample size. A multicenter study with a larger sample size would have given us a better picture. Since asthma is a chronic disease and requires constant supervision, thereby, follow up with patients to multiple visits could have provided us with more information.

\section{CONCLUSION}

The high percentage of asthma patients receiving guideline adhered pharmacotherapy, treatment outcomes were successful. During clinical practice, doctors had to deviate from guidelines based and rely on additional medication and strategies based on their clinical judgement and patient condition to treat patients Attention is needed in selecting a costeffective therapeutic regimen for asthma patients.

\section{ETHICAL APPROVAL AND CONSENT TO PARTICIPATE}

The study was approved by the Ministry of Health and Medical Research Ethics Committee (MREC) Malaysia NMRR-12-1266-14166.

\section{HUMAN AND ANIMAL RIGHTS}

No Animals were used in this research. All human research procedures followed were in accordance with the ethical standards of the committee responsible for human experimentation (institutional and national), and with the Helsinki Declaration of 1975 , as revised in 2008.

\section{CONSENT FOR PUBLICATION}

The study purpose was explained and informed consent was obtained before enrolling study participants.

\section{CONFLICT OF INTEREST}

The authors declare no conflict of interest, financial or otherwise.

\section{ACKNOWLEDGEMENTS}

Declared none.

\section{REFERENCES}

[1] Masoli M, Fabian D, Holt S, Beasley R. The global burden of asthma: executive summary of the GINA Dissemination Committee report. Allergy 2004; 59(5): 469-78. [http://dx.doi.org/10.1111/j.1398-9995.2004.00526.x] [PMID: 15080825]

[2] The global asthma report 2014 Retried from http://www.globalasthmareport.org/burden/burden.php (dated 12/02/2018)

[3] Nurmagambetov T, Kuwahara R, Garbe P. The economic burden of asthma in the United States, 2008 - 2013. Ann Am Thorac Soc 2018; 15(3): 348-56.

[http://dx.doi.org/10.1513/AnnalsATS.201703-259OC] [PMID: 29323930]

[4] Russels B. European Respiratory Society and the Lung Foundation European Lung White Book, (2003).

[5] Browman GP, Levine MN, Mohide EA, et al. The practice guidelines development cycle: A conceptual tool for practice guidelines development and implementation. J Clin Oncol 1995; 13(2): 502-12. [http://dx.doi.org/10.1200/JCO.1995.13.2.502] [PMID: 7844612]

[6] Woolf SH. Practice guidelines: a new reality in medicine. I. Recent developments. Arch Intern Med 1990; 150(9): 1811-8. [http://dx.doi.org/10.1001/archinte.1990.00390200025005] [PMID: 2203320]

[7] Becker AB, Abrams EM. Asthma guidelines: the Global Initiative for Asthma in relation to national guidelines. Curr Opin Allergy Clin Immunol 2017; 17(2): 99-103.

[http://dx.doi.org/10.1097/ACI.0000000000000346] [PMID: 28118238]

[8] Lugtenberg M, Burgers JS, Westert GP. Effects of evidence-based clinical practice guidelines on quality of care: A systematic review. Qual Saf Health Care 2009; 18(5): 385-92. [http://dx.doi.org/10.1136/qshc.2008.028043] [PMID: 19812102]

[9] Jans MP, Schellevis FG, Le Coq EM, Bezemer PD, van Eijk JT. Health outcomes of asthma and COPD patients: the evaluation of a project to implement guidelines in general practice. Inter J Qual Health Care: J Inter Soc Qual Health Care / Isqua 2001; 13(1): 17-25. [http://dx.doi.org/10.1093/intqhc/13.1.17] 
[10] Komajda M, Lapuerta P, Hermans N, et al. Adherence to guidelines is a predictor of outcome in chronic heart failure: the MAHLER survey. Eur Heart J 2005; 26(16): 1653-9. [http://dx.doi.org/10.1093/eurheartj/ehi251] [PMID: 15827061]

[11] Feder G, Griffiths C, Highton C, Eldridge S, Spence M, Southgate L. Do clinical guidelines introduced with practice based education improve care of asthmatic and diabetic patients? A randomised controlled trial in general practices in east London. BMJ 1995; $311(7018)$ : $1473-8$. [http://dx.doi.org/10.1136/bmj.311.7018.1473] [PMID: 8520339]

[12] Cabana MD, Abu-Isa H, Thyne SM, Yawn B. Specialty differences in prescribing inhaled corticosteroids for children. Clin Pediatr (Phila) 2007; 46(8): 698-705. [http://dx.doi.org/10.1177/0009922807301436] [PMID: 17502451]

[13] Grant EN, Moy JN, Turner-Roan K, Daugherty SR, Weiss KB. Asthma care practices, perceptions, and beliefs of Chicago-area primary-care physicians. Chest 1999; 116(4)(Suppl. 1): 145S-54S. [http://dx.doi.org/10.1378/chest.116.suppl_2.145S] [PMID: 10532476]

[14] Sarrell EM, Mandelberg A, Cohen HA, Kahan E. Compliance of primary care doctors with asthma guidelines and related education programs: The employment factor. Isr Med Assoc J 2002; 4(6): 403-6. [PMID: 12073408]

[15] Taylor DM, Auble TE, Calhoun WJ, Mosesso VN Jr. Current outpatient management of asthma shows poor compliance with International Consensus Guidelines. Chest 1999; 116(6): 1638-45. [http://dx.doi.org/10.1378/chest.116.6.1638] [PMID: 10593788]

[16] Stafford RS, Ma J, Finkelstein SN, Haver K, Cockburn I. National trends in asthma visits and asthma pharmacotherapy, 1978-2002. J Allergy Clin Immunol 2003; 111(4): 729-35. [http://dx.doi.org/10.1067/mai.2003.177] [PMID: 12704350]

[17] Roghmann MC, Sexton M. Adherence to asthma guidelines in general practices. J Asthma 1999; 36(4): 381-7. [http://dx.doi.org/10.3109/02770909909068231] [PMID: 10386502]

[18] Navaratnam P, Jayawant SS, Pedersen CA, Balkrishnan R. Physician adherence to the national asthma prescribing guidelines: Evidence from national outpatient survey data in the United States. Ann Allergy Asthma Immunol 2008; 100(3): 216-21. [http://dx.doi.org/10.1016/S1081-1206(10)60445-0] [PMID: 18426140]

[19] Bateman ED, Boushey HA, Bousquet J, et al. Can guideline-defined asthma control be achieved? The Gaining Optimal Asthma ControL study. Am J Respir Crit Care Med 2004; 170(8): 836-44.

[http://dx.doi.org/10.1164/rccm.200401-033OC] [PMID: 15256389]

[20] Stone B, Davis JR, Trudo F, et al. Characterizing patients with asthma who received Global Initiative for Asthma steps 4-5 therapy and managed in a specialty care setting. Allergy Asthma Proc 2018; 39(1): 27-35. [http://dx.doi.org/10.2500/aap.2018.39.4094] [PMID: 29279057]

[21] Choudhry NK, Fletcher RH, Soumerai SB. Systematic review: the relationship between clinical experience and quality of health care. Ann Intern Med 2005; 142(4): 260-73.

[http://dx.doi.org/10.7326/0003-4819-142-4-200502150-00008] [PMID: 15710959]

[22] Janssen-Heijnen ML, Smulders S, Lemmens VEPP, Smeenk FWJM, van Geffen HJ, Coebergh JWW. Effect of comorbidity on the treatment and prognosis of elderly patients with non-small cell lung cancer. Thorax 2004; 59(7): 602-7. [http://dx.doi.org/10.1136/thx.2003.018044] [PMID: 15223870]

[23] Wahba WM. Influence of aging on lung function--clinical significance of changes from age twenty. Anesth Analg 1983; 62(8): 764-76. [http://dx.doi.org/10.1213/00000539-198308000-00011] [PMID: 6346955]

[24] Apostol GG, Jacobs DR Jr, Tsai AW, et al. Early life factors contribute to the decrease in lung function between ages 18 and 40 : The Coronary Artery Risk Development in Young Adults study. Am J Respir Crit Care Med 2002; 166(2): 166-72. [http://dx.doi.org/10.1164/rccm.2007035] [PMID: 12119228]

[25] Korn S, Schumann C, Kropf C, et al. Effectiveness of omalizumab in patients 50 years and older with severe persistent allergic asthma. Ann Allergy Asthma Immunol 2010; 105(4): 313-9. [http://dx.doi.org/10.1016/j.anai.2010.07.007] [PMID: 20934632]

[26] Hoskins G, McCowan C, Thomas G, Smith B, Everhard F. Identifying the characteristics and costs of treating 'poorly controlled' asthma patients. Eur Respir Rev 2001; 18(Suppl. 33): 329s.

[27] McCowan C, Hoskins G, Everhard F, Smith B, Thomas G. Do patients with high-risk asthma suffer increased absenteeism. Am J Respir Crit Care Med 2002; 8: A120.

(C) 2018 Aftab et al.

This is an open access article distributed under the terms of the Creative Commons Attribution 4.0 International Public License (CC-BY 4.0), a copy of which is available at: https://creativecommons.org/licenses/by/4.0/legalcode. This license permits unrestricted use, distribution, and reproduction in any medium, provided the original author and source are credited. 